\title{
Clinical Trial Agent
}

National Cancer Institute

\section{Source}

National Cancer Institute. Clinical Trial Agent. NCI Thesaurus. Code C90373.

The pharmacological substance that is being administered in the study. 